\title{
PERANCANGAN APLIKASI PENGELOLAAN DATA DAN KEUANGAN WARGA WILAYAH BAMBU APUS BERBASIS JAVA
}

\author{
Taufan Harisaputra \\ Teknik Informatika, Fakultas Teknik dan Ilmu Komputer, Universitas Indraprasta PGRI \\ Jalan Raya Tengah No 80, Kelurahan Gedong, Pasar Rebo, Jakarta Timur \\ saputra.taufan17@gmail.com
}

\begin{abstract}
ABSTRAK
Pengelolaan data dan keuangan warga di wilayah RT 003 RW 02 Kelurahan Bambu Apus Kecamatan Cipayung Jakarta Timur masih menggunakan cara manual dengan mencatat ke dalam pembukuan atau arsip. Tujuan penelitian ini adalah membangun sebuah aplikasi untuk mendukung dan mempermudah pengurus RT dalam mengelola data dan keuangan warga. Metode penelitian ini menggunakan Metode Research and Development (R\&D) yaitu metode penelitian yang digunakan untuk menghasilkan produk tertentu, dan menguji keefektifan produk tersebut. Metode pengumpulan data yang digunakan terdiri dari observasi, wawancara dan studi kepustakaan. Hasil dari penelitian ini adalah sebuah rancangan aplikasi pengelolaan data dan keuangan warga berbasis java yang sudah dirancang dan dibuat sesuai dengan kebutuhan pada RT 003 RW 02 Kelurahan Bambu Apus Kecamatan Cipayung Jakarta Timur. Dalam melewati tahap pengujian pembuatan aplikasi pengelolaan data dan keuangan warga ini, implementasi untuk aplikasi ini mampu memberikan kemudahan dalam penggunaannya serta keakuratan data yang disimpan ke dalam database komputer.
\end{abstract}

Kata Kunci: Aplikasi, Java, Data Warga, Keuangan, Research and Development.

\begin{abstract}
The management of data and financial residents in RT 003 RW 02 Bambu Apus Village, Cipayung District, East Jakarta, still uses manual methods by recording into bookkeeping or archives. This research aims to build an application to support and facilitate RT administrators in managing citizens' data and finances. This research method uses the Research and Development $(R \& R \& D)$ method, which is used to produce a particular product and tests the effectiveness of the product. The data collection method used consists of observation, interview and literature studies. The result of this study is a design application for data management and javabased citizen finances that has been designed and made by the needs of RT 003 RW 02 Bambu Apus Village, Cipayung District, East Jakarta. In passing the testing phase of making data management and citizen finance applications, the implementation for this application can provide ease of use and accuracy of data stored into computer databases.
\end{abstract}

Key Word: Application, Java, Citizen Data, Finance, Research and Development.

\section{PENDAHULUAN}

Dalam sebuah organisasi, kecepatan dalam mengakses data dan penyampaian suatu informasi merupakan salah satu media pendukung untuk berkembang dengan baik. Hal ini dikarenakan, suatu sistem informasi yang ideal akan mampu meningkatkan kinerja suatu organisasi, yang akhirnya dapat mewujudkan sebuah kemajuan bagi organisasi tersebut. Salah satunya adalah sistem informasi data dan keuangan warga yang dibangun untuk mendukung proses pengelolaan data dan keuangan warga dalam lingkup RT .

Tugas RT adalah menjadi perpanjangan tangan pemerintah daerah dalam menjalankan tugas pelayanan kepada masyarakat, menyerap aspirasi masyarakat, membantu pendataan kependudukan dan administrasi pemerintah, membantu terciptanya ketentraman, ketertiban dan kerukunan antar warga serta menggerakan swadaya masyarakat melalui gotong royong dalam pemberdayaan masyarakat guna menciptakan lingkungan yang aman, bersih tertib dan lestari (Sony \& Sabaruddin, 2020).

Pada saat ini sistem pengelolaan data dan keuangan warga di wilayah RT 003 RW 02 Kelurahan Bambu Apus Kecamatan Cipayung Jakarta Timur masih menggunakan cara manual dengan mencatat ke dalam pembukuan atau arsip yang menyebabkan rawan terjadinya duplikasi data yang dapat mengakibatkan ketidakakuratan data dalam 
pengelolaannya. Media penyimpanan pengarsipan berbentuk dokumen tentu rentan rusak atau hilang serta membutuhkan banyak tempat untuk arsip itu disimpan.

Permasalahan yang masih sering terjadi adalah masih banyak warga pendatang atau pindahan sering tidak melapor pada aparat setempat dan mempunyai identitas ganda terutama di kalangan pelajar dan mahasiswa, juga banyak warga yang sering mengabaikan dalam proses kelahiran, kematian, perkawinan, penerbitan kartu keluarga baru (Ibrahim et al., 2016).

Permasalahan yang sering terjadi dalam keuangan RT juga salah satunya pada saat pembayaran iuran warga yang tidak tercatat pada pencatatan bendahara di karenakan lupa tercatat atau kartu yang hilang (Rahmawati \& Ridwan, 2021).

Berdasarkan permasalahan yang dihadapi oleh pengurus RT 003 RW 02 Kelurahan Bambu Apus Kecamatan Cipayung Jakarta Timur maka diperlukan pembuatan sebuah aplikasi untuk mendukung dan mempermudah pengurus RT dalam mengelola data dan keuangan warga.

Perancangan sistem adalah penentuan proses dan data yang diperlukan oleh sistem baru yang bertujuan untuk memenuhi kebutuhan pengguna sistem serta untuk memberikan gambaran yang jelas dan rancang bangun yang lengkap (Mulyani, 2017).

Manusia, komputer, teknologi informasi, dan prosedur kerja adalah komponen yang mencakup dalam sistem informasi, proses data menjadi suatu informasi dimaksudkan untuk mencapai suatu tujuan atau sasaran (A Kadir, 2014).

5 (lima) komponen yang harus dimiliki suatu sistem informasi agar berjalan dengan baik diantaranya adalah hardware dan software, prosedur, pengguna dan database (Haswan, 2018).

Dalam setiap organisasi haruslah memiliki laporan keuangan untuk menunjang kegiatan organisasi tersebut. Yang dimaksud laporan keuangan disini adalah laporan yang menunjukkan kondisi keuangan suatu organisasi dari periode saat ini hingga periode kedepannya. Maksud dan tujuan laporan keuangan menunjukkan kondisi keuangan organisasi tersebut (Kasmir, 2013).

Bahasa pemrograman yang digunakan untuk merancang aplikasi ini adalah bahasa pemrograman java dengan Netbeans sebagai editornya yang merupakan sebuah aplikasi Integrated Development Environment (IDE) yang menggunakan bahasa pemograman java yang berjalan di atas swing (Nofriadi, 2015).

Karena Java adalah nama sebuah bahasa pemrograman berorientasi objek yang sangat terkenal yang dikembangkan di Sun Microsystems sehingga memudahkan dalam pembuatan aplikasi yang berskala besar (Abdul Kadir, 2014).

Dalam pengelolaan database menggunakan MySQL yang merupakan database server yang banyak digunakan untuk membangun aplikasi (Rudyanto, 2011).

Tujuan dari penelitian ini yaitu untuk merancang suatu aplikasi pengelolaan data dan keuangan warga untuk memberikan kemudahan bagi pengurus RT dalam mengelola data dan keuangan warganya.

Manfaat dari penelitian ini adalah menghasilkan sebuah aplikasi pengelolaan data dan keuangan warga yang dapat mendukung kinerja RT/RW, mempermudah warga untuk berkomunikasi dengan Pengurus RT dan mendapatkan layanan surat pengantar dari RT/RW.

Urgensi atau keutamaan dalam penelitian ini adalah dapat mendukung program pemerintah dalam mengembangkan Smart City. Memudahkan pengurus RT dalam melakukan manajemen administratif dan publikasi kegiatan-kegiatan serta penanganan laporanlaporan warga.

\section{METODE PENELITIAN}

Penelitian Perancangan Aplikasi Pengelolaan Data dan Keuangan Warga ini bertempat di Lingkungan RT 003 RW 02 Kelurahan Bambu Apus Kecamatan Cipayung Jakarta Timur.

Metode penelitian ini menggunakan Metode Research and Development (R\&D) yaitu metode penelitian yang digunakan untuk menghasilkan produk tertentu, dan menguji keefektifan produk tersebut. Metode 
pengumpulan data yang digunakan terdiri dari observasi, wawancara dan studi kepustakaan. Untuk pengembangan perangkat lunak yang digunakan adalah metode pengembangan perangkat lunak model prototype. Metode prototype memudahkan user dalam berinteraksi dengan sistem dan memahami kekurangan dari sistem tersebut sesuai dengan kebutuhan dari pengguna.

Berikut gambar tahapan yang dilakukan dalam melakukan penelitian ini.

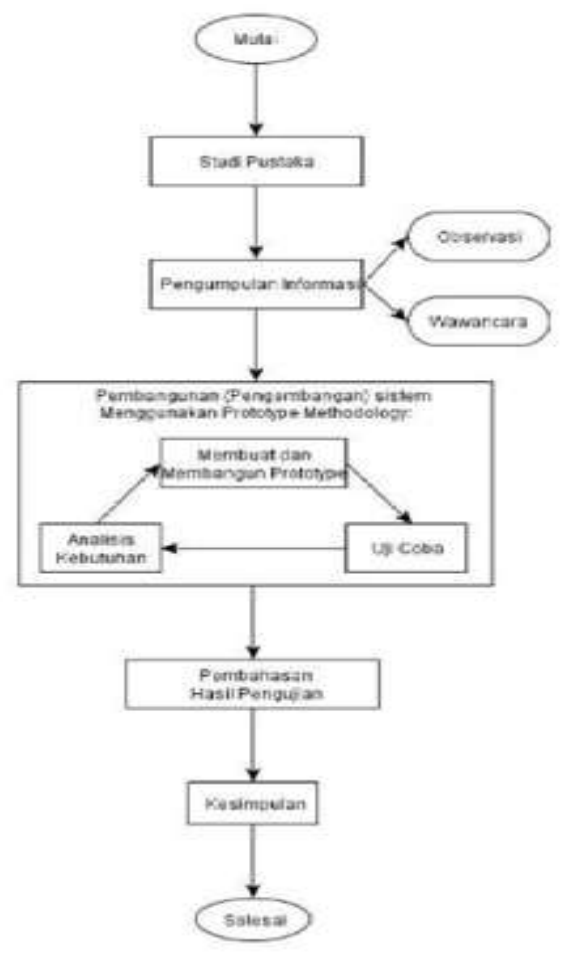

Gambar 1. Tahapan Penelitian

\section{HASIL DAN PEMBAHASAN}

Melihat permasalahan pada sistem yang sedang berjalan dalam pengelolaan data dan keuangan warga, maka peneliti memberikan usulan sistem dan aturan bisnis dalam Sistem Pengelolaan Data dan Keuangan Warga pada RT 003 RW 02 sebagai berikut:

1. Pengurus RT melakukan pendataan (sensus) kepada setiap warganya.

2. Pengurus RT melakukan input data ke dalam sistem dan disimpan ke dalam database sebagai informasi data warga.

3. Setiap bulannya pengurus RT melakukan penarikan iuran warga (iuran sampah, iuran keamanan, iuran kas dan iuran yang lainnya) yang dicatat pada kartu iuran.
4. Pengurus RT melalui bendahara melakukan rekap data iuran warga dan mencetak laporan keuangan kas RT setiap bulannya yang selanjutnya akan di informasikan kepada semua warga di lingkungan RT 003 RW 02.

Berikut adalah gambaran sistem berjalan dalam bentuk Diagram Alir Data (DAD) diagram konteks sistem berjalan:

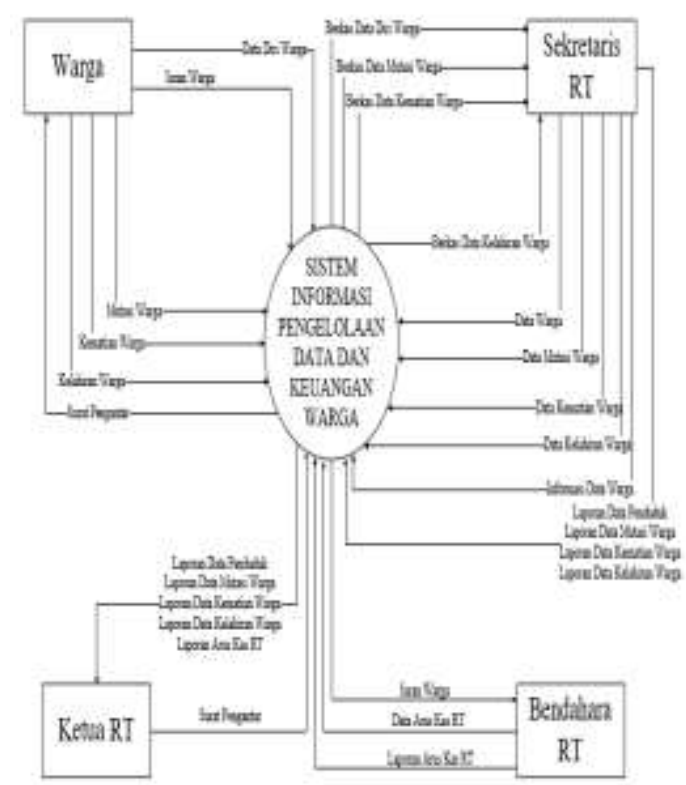

Gambar 2. Diagram Konteks Sistem Berjalan

Diagram Alir Data (DAD) merupakan suatu diagram yang menggambarkan aliran data yang penggambarannya disusun dalam bentuk kumpulan komponen sistem yang saling berhubungan (Sutabri, 2012).

Lalu berikut adalah penggambaran tentang sistem yang diusulkan dalam bentuk diagram konteks sistem yang diusulkan dan diagram nol sistem yang diusulkan:

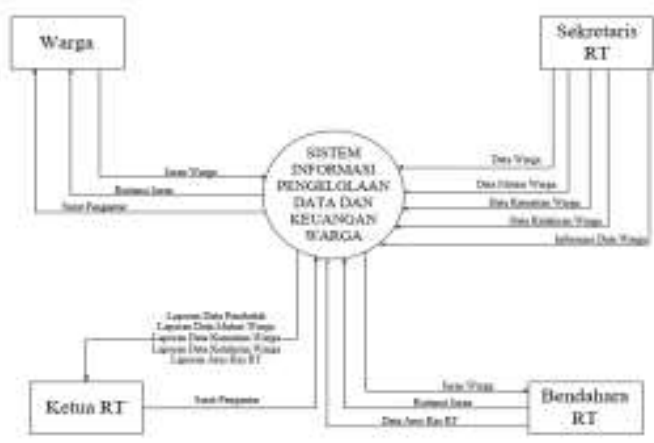

Gambar 3. Diagram konteks sistem yang diusulkan 


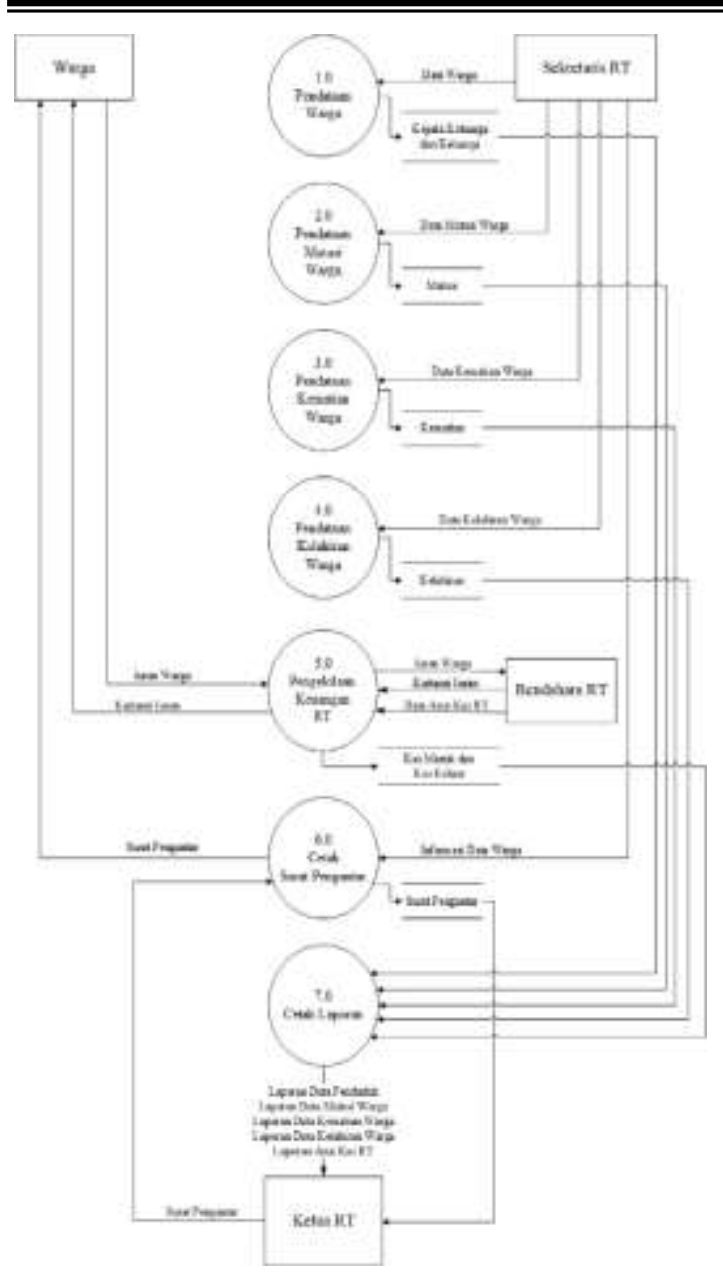

Gambar 4. Diagram Nol Sistem yang Diusulkan

\section{ERD (Entity Relationship Diagram)}

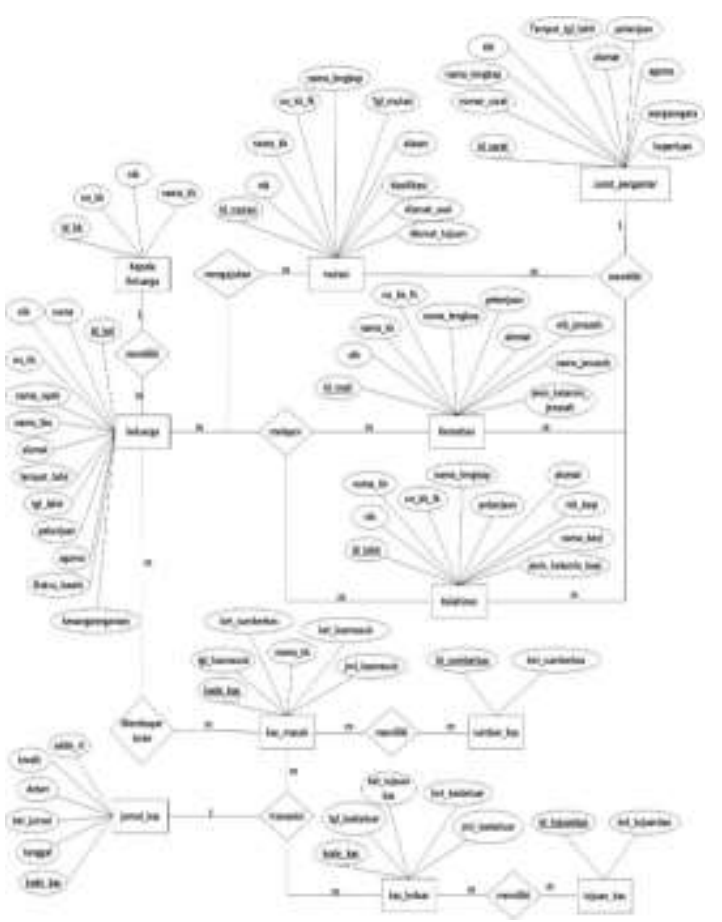

Gambar 5. ERD (Entity Relationship Diagram)
Dari gambaran diagram di atas, selanjutnya diimplementasikan ke dalam sistem yang menghasilkan suatu aplikasi pengelolaan data dan keuangan warga berbasis java dengan tampilan layar sebagai berikut:

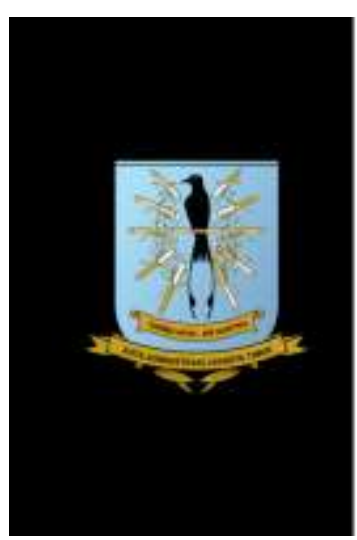

Aplikasi Data RT

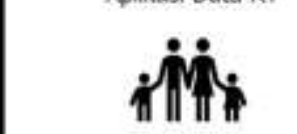

was iompen

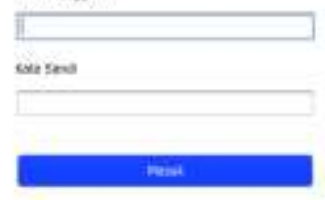

Gambar 6. Tampilan Menu Login

Tampilan ini terdapat pada awal program. Menu login digunakan sebagai kata kunci sebelum memasuki program utama yang hanya bisa diakses oleh pengguna tertentu saja yang memiliki Nama pengguna dan kata sandi yang sudah ditentukan.

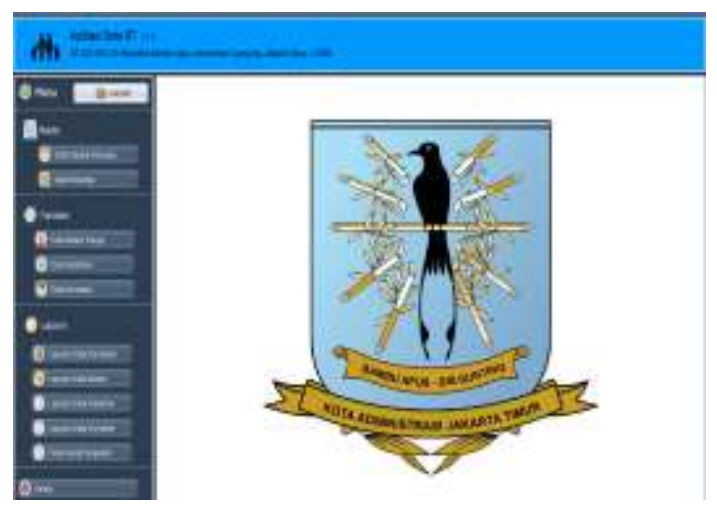

Gambar 7. Tampilan Menu Utama

Di dalam tampilan menu utama terdapat beberapa pilihan menu yaitu:

1. Kas RT yang berfungsi untuk melakukan input segala transaksi kas RT.

2. Data Kepala Keluarga untuk menampilkan form data kepala keluarga yang berfungsi untuk melakukan input data kepala keluarga.

3. Data Keluarga untuk menampilkan form data keluarga yang berfungsi untuk melakukan input data keluarga. 
4. Data Mutasi Warga untuk menampilkan form data mutasi warga yang berfungsi untuk melakukan input data mutasi warga.

5. Data Kelahiran untuk menampilkan form data kelahiran yang berfungsi untuk melakukan input data kelahiran..

6. Data Kematian untuk menampilkan form data kematian yang berfungsi untuk melakukan input data kematian.

7. Laporan untuk mencetak berbagai laporan seperti laporan data penduduk, laporan data mutasi warga, laporan kelahiran, laporan kematian.

8. Cetak Surat Pengantar untuk menampilkan form cetak surat pengantar yang digunakan warga untuk keperluan administrasi warga.

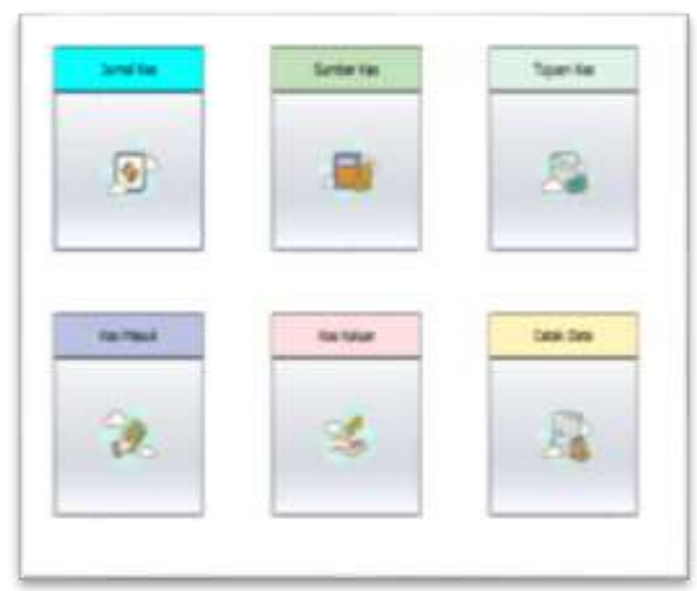

Gambar 8. Tampilan Menu Kas RT

Di dalam menu kas RT terdapat beberapa menu yaitu:

1. Sumber Kas untuk menampilkan form sumber kas masuk yang berfungsi untuk memberikan kode dan kategori pada kas masuk.

2. Tujuan Kas untuk menampilkan form tujuan kas keluar yang berfungsi untuk memberikan kode dan kategori pada kas keluar.

3. Kas Masuk untuk menampilkan form kas masuk yang berfungsi untuk melakukan input kas masuk berdasarkan kategori pada sumber kas dan untuk mencetak kuitansi iuran warga sebagai tanda terima pembayaran iuran.

4. Kas keluar untuk menampilkan form kas keluar yang berfungsi untuk melakukan input kas keluar berdasarkan kategori pada tujuan kas.

5. Jurnal kas untuk menampilkan transaksi kas masuk dan kas keluar dan juga untuk melihat saldo balance kas rt.

6. Cetak Data untuk mencetak laporan Kas masuk, kas keluar, dan jurnal kas RT dengan periode tertentu.

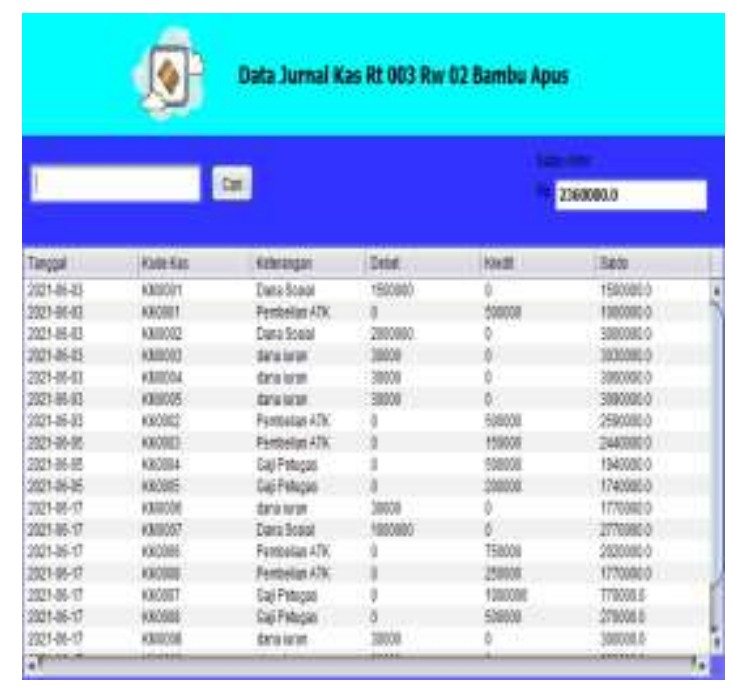

Gambar 9. Tampil Layar Jurnal kas RT

Gambar di atas merupakan tampilan jurnal kas yang menampilkan keseluruhan transaksi kas masuk, kas keluar dan sisa saldo pada kas RT.

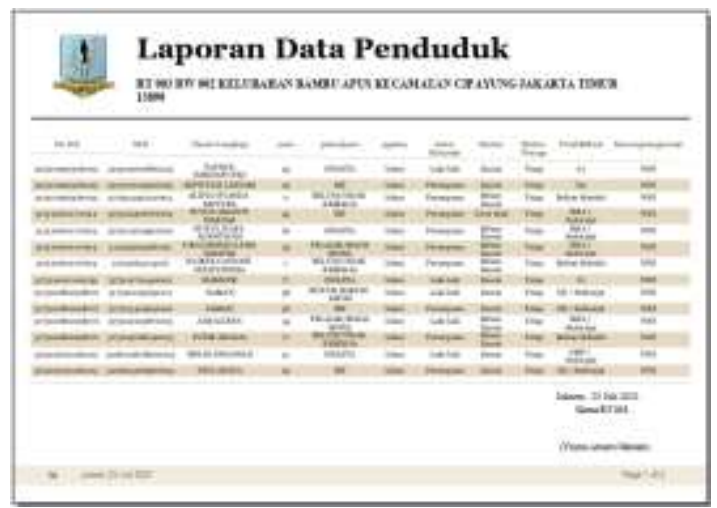

Gambar 10. Cetak Laporan Data Penduduk

Gambar di atas merupakan cetak laporan data penduduk yang menampilkan seluruh data penduduk yang tercatat di lingkungan RT 003 RW 02. 


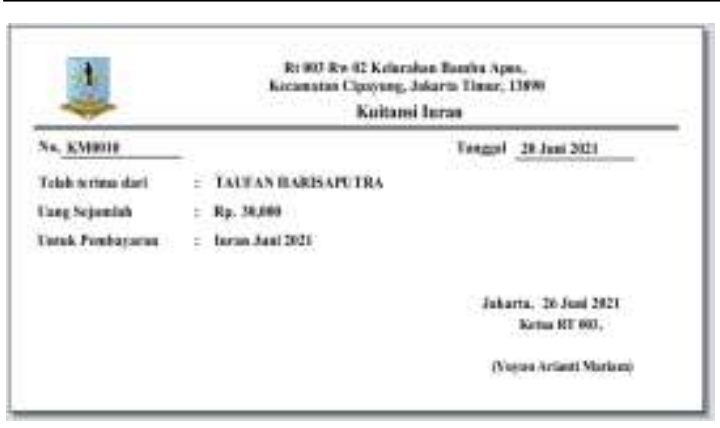

Gambar 11. Cetak Kuitansi Iuran Warga

Gambar di atas merupakan cetak kuitansi iuran warga sebagai tanda bukti pembayaran iuran warga yang diterima warga setelah melakukan pembayaran iuran bulanan.

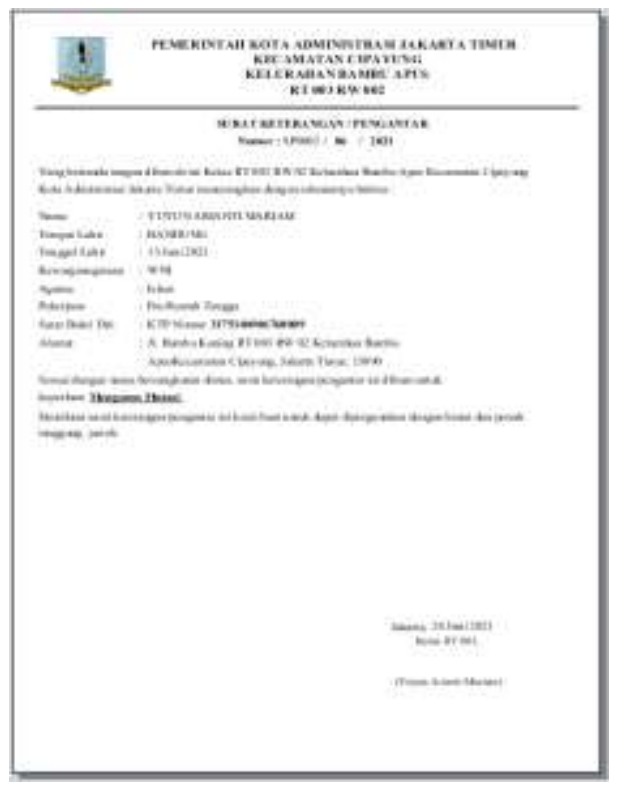

Gambar 12. Cetak Surat Pengantar

Gambar di atas merupakan cetak surat pengantar yang diberikan ke warga bila ada warga yang memerlukan surat pengantar untuk pengurusan administrasi warga.

\section{SIMPULAN DAN SARAN}

Berdasarkan hasil dari penelitian yang telah dilakukan dalam perancangan aplikasi sistem informasi pengelolaan data dan keuangan warga RT 003 RW 02 Kelurahan Bambu Apus Kecamatan Cipayung Jakarta Timur, maka peneliti dapat menarik simpulan bahwa perancangan aplikasi pengelolaan data dan keuangan warga sudah dirancang dan dibuat sesuai dengan kebutuhan pada RT 003 RW 02 Kelurahan Bambu Apus Kecamatan Cipayung Jakarta Timur.
Dalam melewati tahap pengujian, implementasi untuk aplikasi ini mampu memberikan kemudahan dalam pengelolaan data karena data disimpan ke dalam database komputer.

Penggunaan sistem aplikasi ini dapat memberikan kemudahan serta manfaat lebih kepada pengurus RT dan warganya dalam meningkatkan efektifitas agar lebih efisien dalam mengelola data warga dan mengelola keuangan RT.

Saran untuk pengembangan aplikasi ini selanjutnya, maka sistem yang dirancang dan dibuat dapat menyempurnakan penelitian sebelumnya, baik dari segi metode penelitian maupun tampilan aplikasi yang dapat mempermudah penggunaan aplikasi serta dapat menyesuaikan kebutuhan di kemudian hari.

\section{UCAPAN TERIMA KASIH}

Peneliti mengucapkan terima kasih kepada segenap pengurus RT 003 RW 02 kelurahan bambu apus kecamatan cipayung jakarta timur yang sudah bersedia memberikan tempat untuk penelitian ini dan memberikan segala yang dibutuhkan untuk menunjang penelitian ini.

\section{DAFTAR PUSTAKA}

Haswan, F. (2018). Perancangan Sistem Informasi Pendataan Penduduk Kelurahan Sungai Jering Berbasis Web Dengan Object Oriented Programming. Jurnal Teknologi Dan Open Source, 1(2), 92-100. https://doi.org/10.36378/jtos.v1i2.23

Ibrahim, A., Rifai, A., \& Oktarina, L. (2016). Rancang Bangun Aplikasi Pencatatan Data Kependudukan Kelurahan Pahlawan Berbasis Web. Jurnal Sistem Informasi, 8(1), 947-957.

Kadir, A. (2014). Pengenalan sistem informasi edisi revisi. Yogyakarta: Andi, 2.No Title. Edisi Revisi, January. https://doi.org/10.13140/2.1.2637.6328

Kadir, Abdul. (2014). Buku Pertama Belajar Pemrograman Java Untuk Pemula. Yogyakarta: Andi. January 2014, 444. https://doi.org/10.13140/2.1.3686.2084

Kasmir. (2013). Bank dan Lembaga 
Keuangan Lainnya. Jakarta: PT. Raja Grafindo Persada.

Mulyani, S. (2017). Metode Analisis dan Perancangan Sistem. (M. Sri (ed.); Kedua). Bandung: Abdi Sistematika.

Nofriadi. (2015). Java Fundamental Dengan Netbeans 8.0.2. Yogyakarta: (Deepublish (ed.)).

Rahmawati, N. D., \& Ridwan, R. (2021). Sistem Informasi Dan Keuangan Warga $R t$ / Rw 03 / 01 Kecamatan Cilodong Kelurahan Cilodong Depok - Jawa Barat. 414-419.

Rudyanto, A. M. (2011). Pemrograman Web
Dinamis menggunakan PHP dan $M y S Q L$. Yogyakarta: Andi.

Sony, M., \& Sabaruddin, R. (2020). Rancang Bangun Dashboard Smart System Manajemen RT / RW Design and Build a Smart RT-RW Management System Dashboard to Support Society 5 . 0. 8(2), 328-332.

https://doi.org/10.26418/justin.v8i4.425 86

Sutabri, T. (2012). Analisis Sistem Informasi. Yogyakarta: Andi. 